\title{
In Memorian
}

\section{Frank A. Chervenak* \\ Robert L. Brent, MD, PhD (1927-2021)}

https://doi.org/10.1515/.jpm-2021-0136

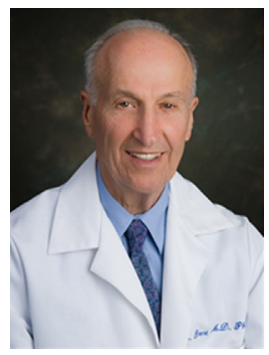

On February 24, 2021 the world lost one of the greatest perinatologists of all time, Robert L. Brent, MD, PhD. Dr. Brent began his career at the age of 15 when he was accepted to the University of Rochester and obtained part-time employment in the embryology and genetics divisions of the Manhattan Project of the University of Rochester. In his 11 years at the university, he eventually became head of the embryology division while he was a graduate and medical student. After graduating from the University of Rochester Medical School in 1953, he interned at the Massachusetts General Hospital. Subsequently, he became Chief of Radiation Biology at Walter Reed Army Institute of Research before moving to Thomas Jefferson Medical College, where he performed research, taught and cared for patients for over 60 years. At Jefferson, he specialized in the effects of environmental factors like radiation, drugs, and chemicals on the fetal patient. He was chairman of the Department of Pediatrics for 30 years, during which time his research was continuously funded by the National Institutes of Health.

Dr. Brent's research has demonstrated that birth defects, growth retardation, mental retardation, and miscarriage are all threshold effects of radiation exposure, and that the vast majority of diagnostic radiological tests do not pose an additional measurable risk to the fetal patient. These findings have been important for advising women

*Corresponding author: Frank A. Chervenak, MD, Chair of Obstetrics and Gynecology, Lenox Hill Hospital, New York, USA; and Professor and Chair of Obstetrics and Gynecology and Associate Dean for International Medicine, Zucker School of Medicine at Hofstra/ Northwell, New York, USA, E-mail: fchervenak@northwell.edu about the risks of cancer treatment or diagnostic radiological procedures during pregnancy. Other significant research contributions include the discovery that although very young embryos are extremely vulnerable to radiation, those that survive are not at increased risk for congenital malformations (a finding called the "all or none" phenomenon); and the development of a systematic methodology for evaluating the risk of reproductive toxicants.

Throughout his career, first by letter and telephone and finally through the Internet, Dr. Brent has offered free risk counseling to expectant mothers worldwide. He has written and lectured extensively on the importance of training physicians to counsel pregnant women and their families with patience and compassion-and with a focus on education and empowerment.

Dr. Brent was a member of the National Academy of Medicine and has received a multitude of national and international awards, including the John Scott Award "for being the foremost authority in the world on the effects of radiation on the human embryo and in the causes and prevention of congenital malformations"; the William Liley Medal; the Taylor prize (the highest award of the National Council on Radiation Protection and Measurements); the Robley D. Evans Commemorative Medal of the Health Physics Society for lifelong contributions to the field of radiation biology and embryology; and the Distinguished Professor Award of Thomas Jefferson University (only three people have received this award in the 175 year history of Jefferson Medical College).

On a personal note, Dr. Brent has been a mentor and friend for many years. A sentinel moment in my life was the first day of medical school when Dr. Brent presented "Medicine, An Excuse from Living” emphasizing the importance of prioritizing ones family. More than any other American pediatrician, he supported international perinatology and our affiliated societies in which he actively participated. All who had the gift of being with him and learning from him will always treasure this experience. He melded scientific excellence and professional virtues in a unique and beautiful way.

He died peacefully surrounded by his many adoring children and grandchildren. His beloved wife, Lillian, of 60 years had passed only a few months earlier. Bob will live on in the hearts and minds of not just his family - but of perinatologists throughout the world. 